Article DOI: http://dx.doi.org/10.3201/eid1909.130087

\title{
Highly Pathogenic Avian Influenza A(H7N3) Virus in Poultry Workers, Mexico, 2012
}

\section{Technical Appendix}

Technical Appendix Figure (following pages). Phylogenetic trees of A) polymerase basic 2, B) polymerase basic 1, C) polymerase acidic, D) nucleoprotein, E) matrix, and F) nonstructural protein genes of highly pathogenic avian influenza (HPAI) $A(H 7 N 3)$ virus isolated from a poultry worker with conjunctivitis in Jalisco State, Mexico, July 2012, and other influenza viruses. HPAI A(H7N3) viruses from Mexico indicated in boldface. Bootstrap values $>60$ are shown above or below branches in each tree. *Indicates viruses detected in 2011 or 2012 . Scale bars indicate nucleotide substitutions per site. 


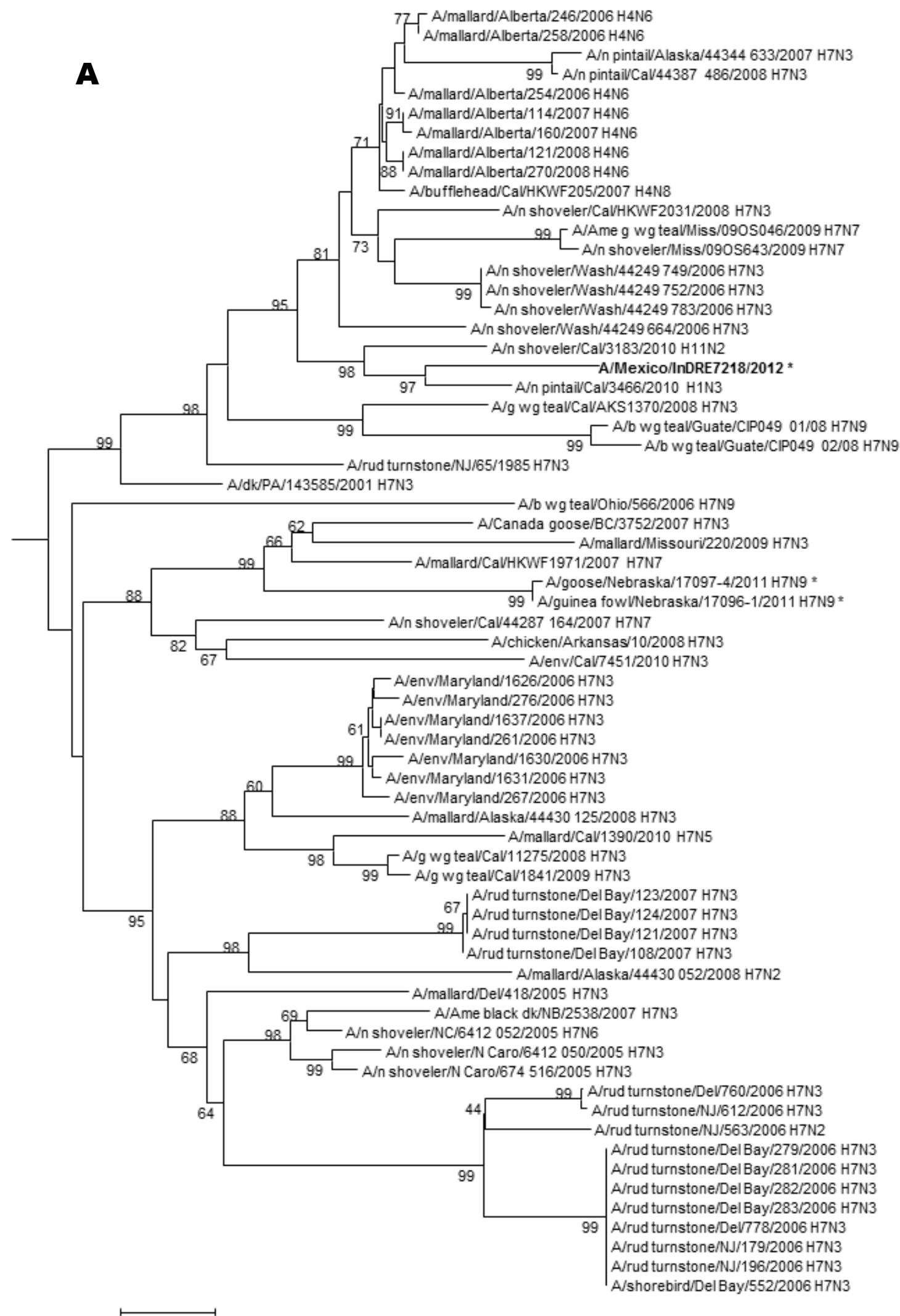




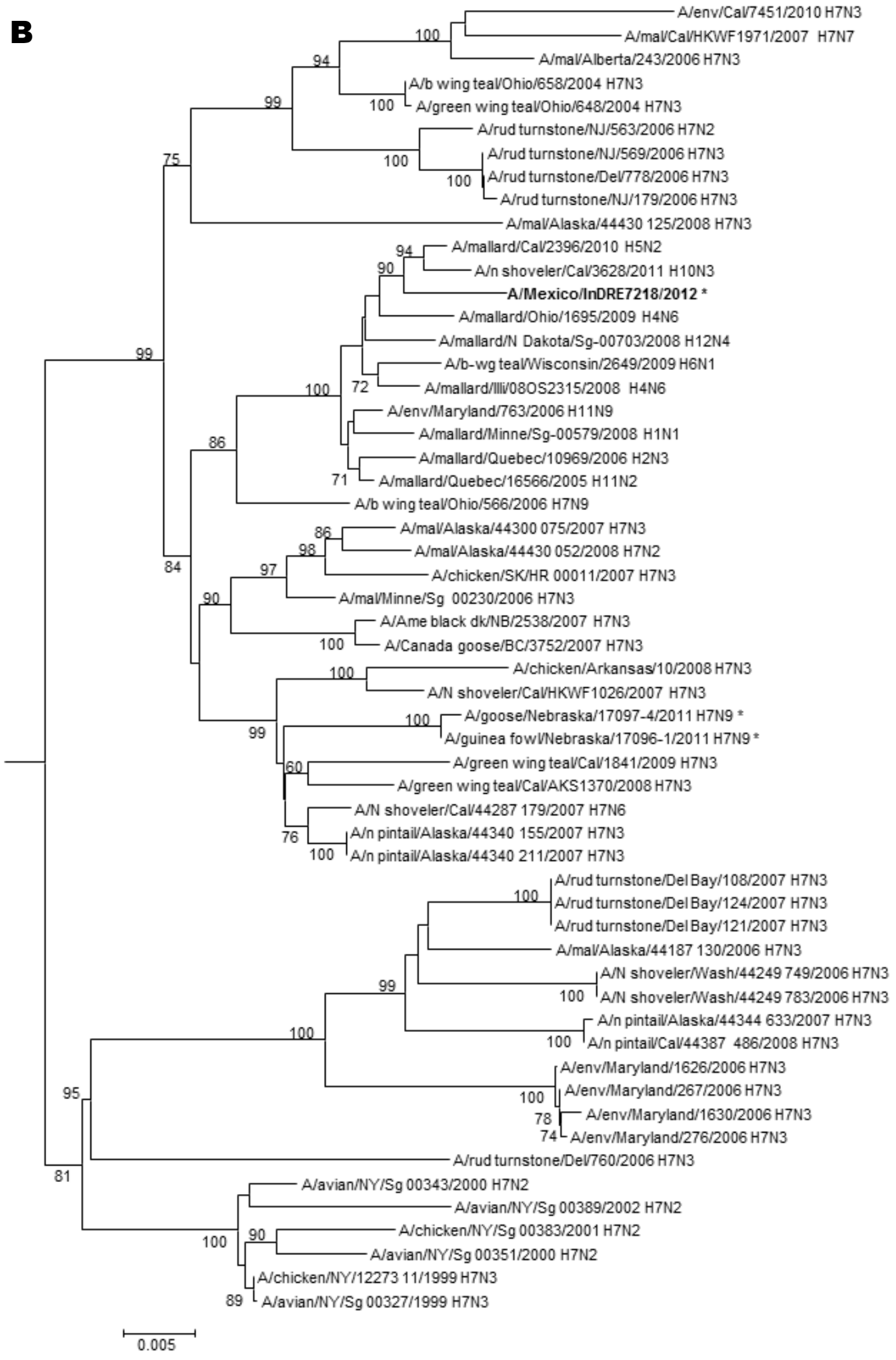

Page 3 of 7 


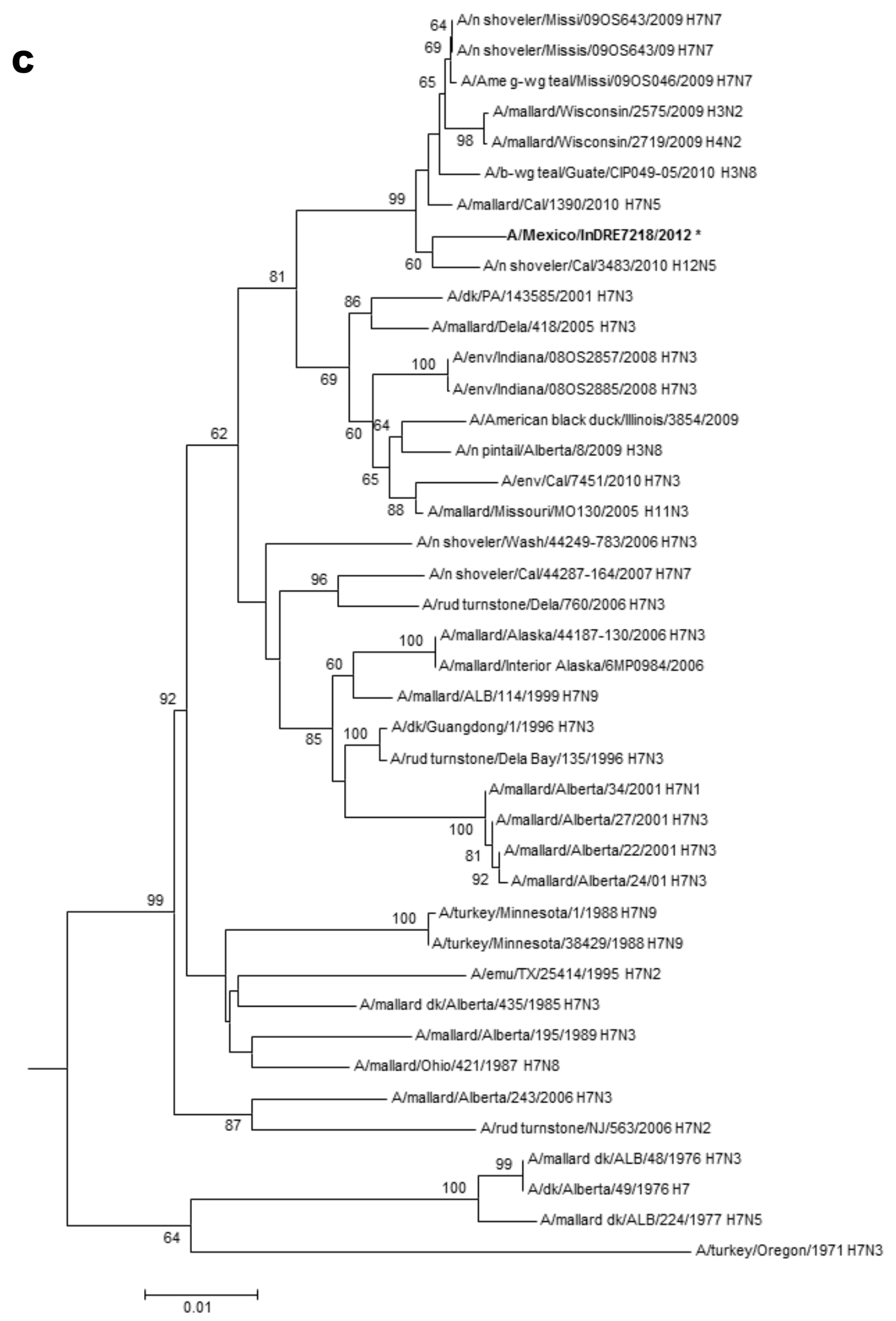

Page 4 of 7 
D

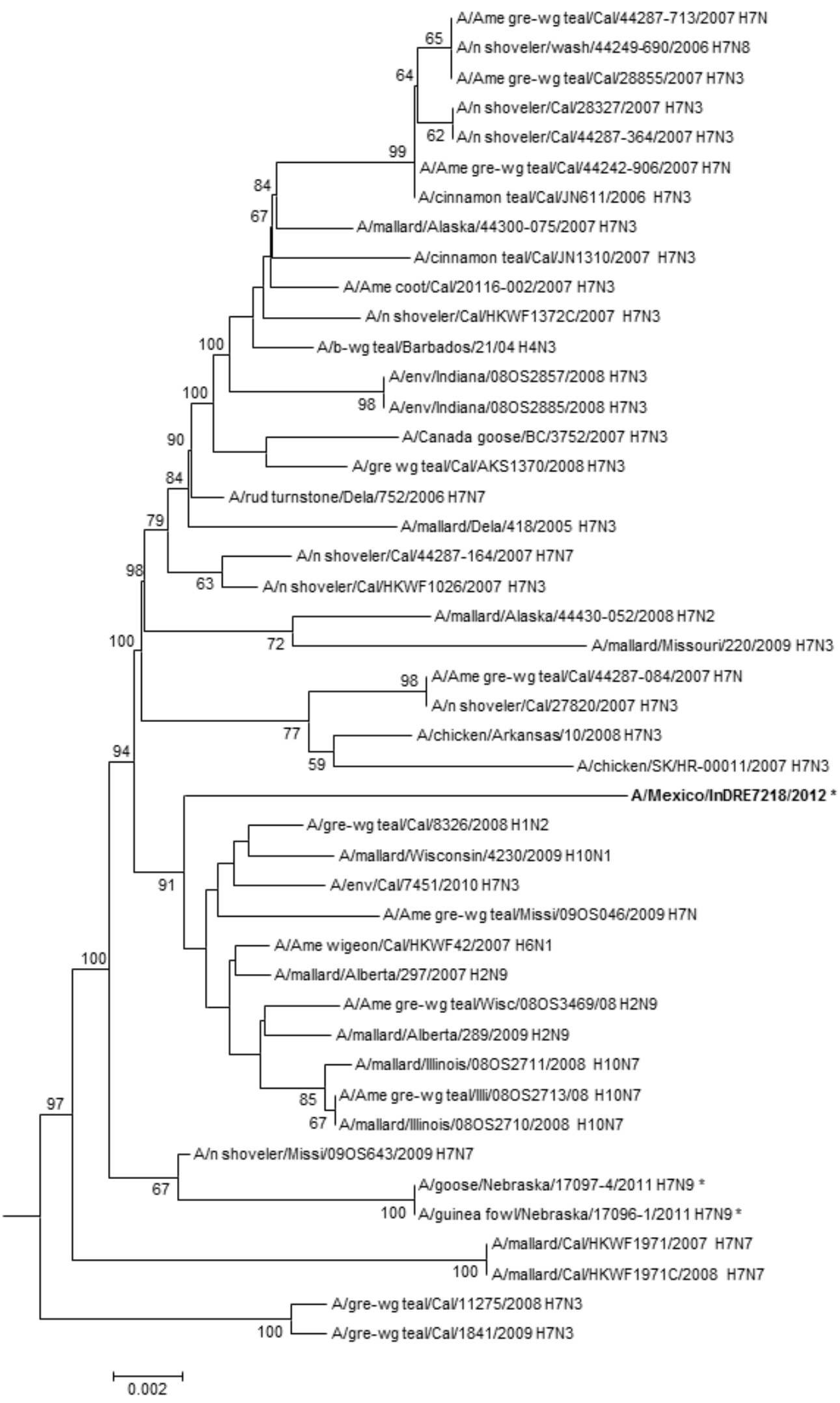

Page 5 of 7 


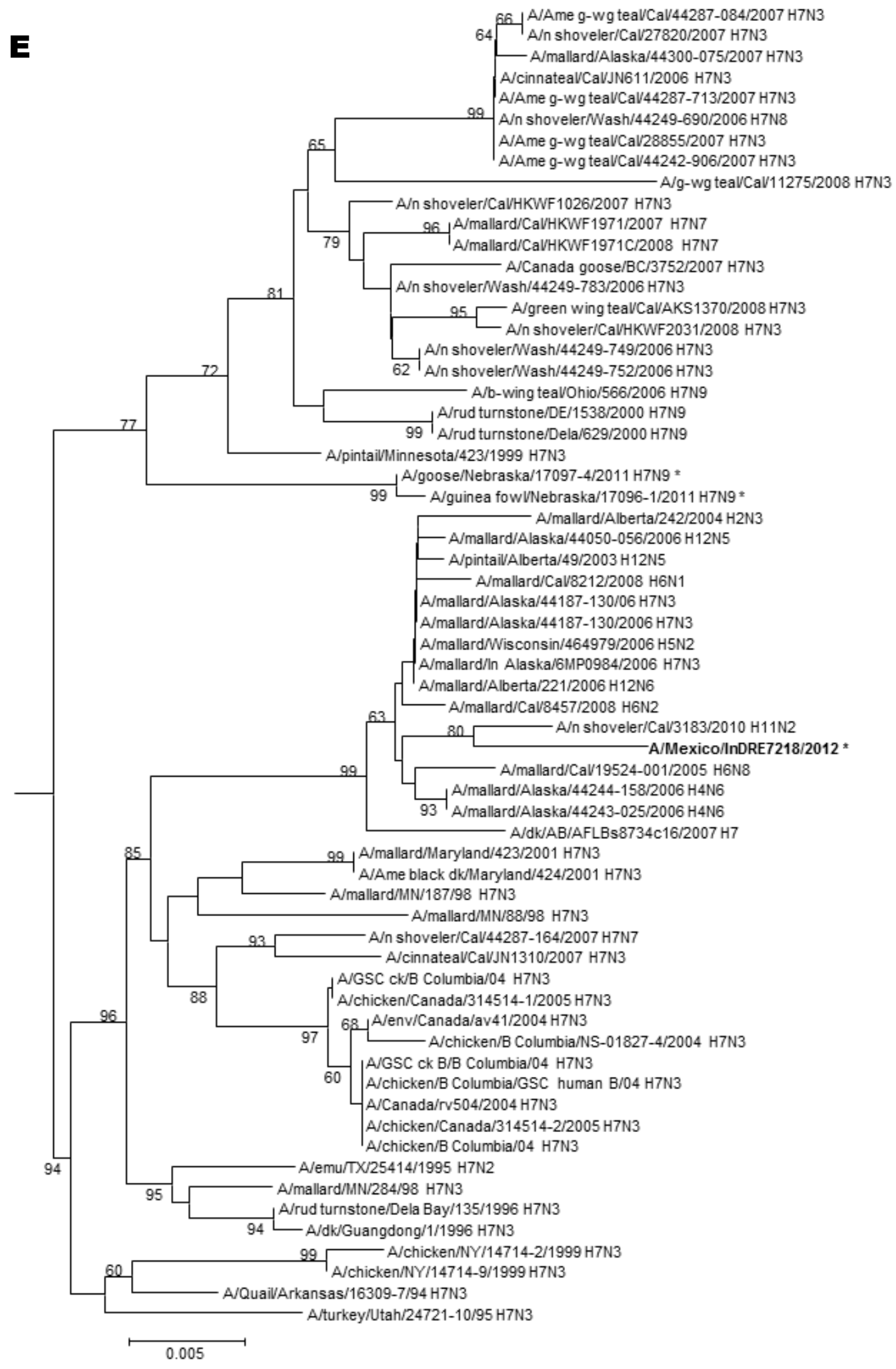

Page 6 of 7 


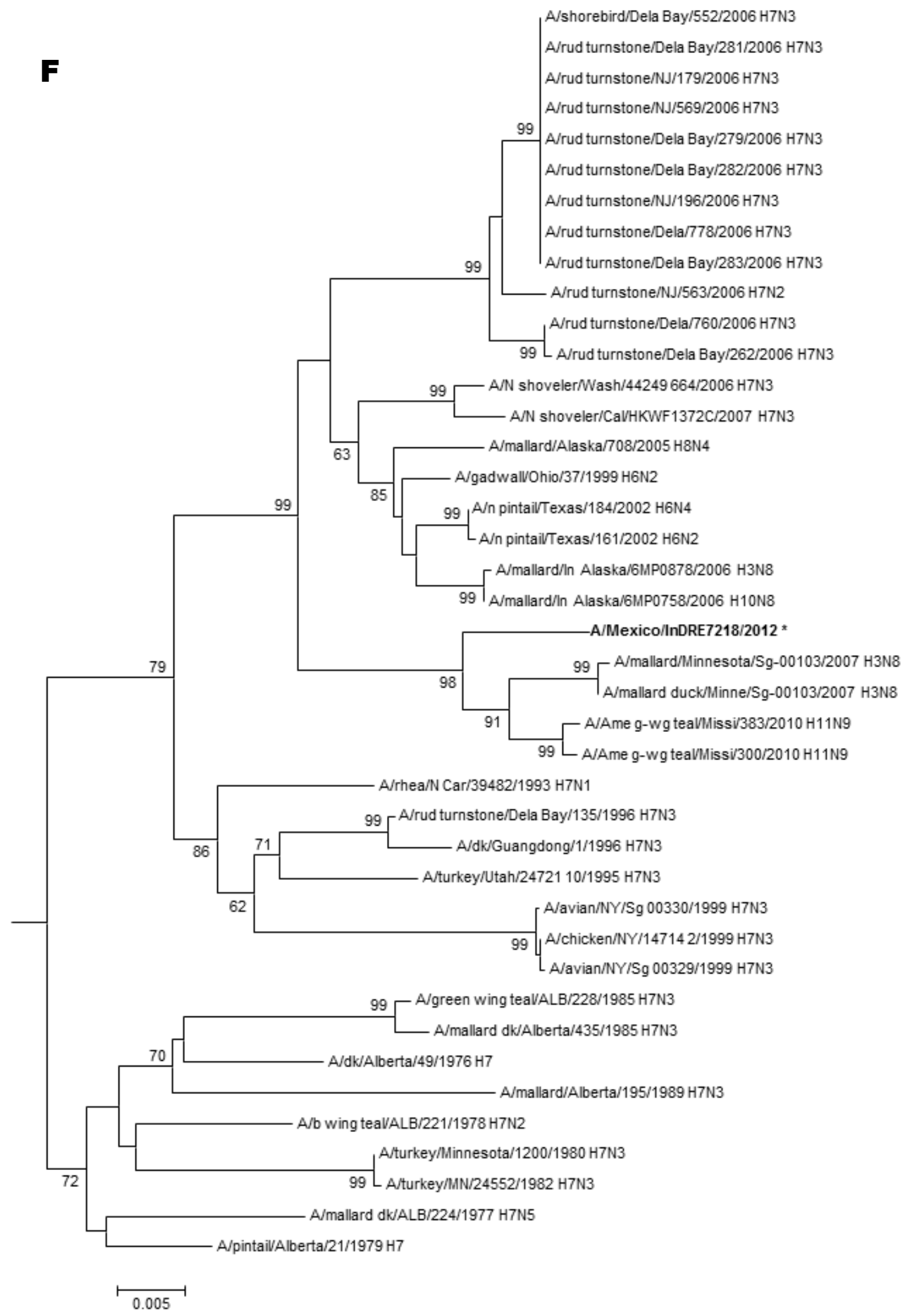

Page 7 of 7 